\title{
Memoria histórica, cuerpo y performance. Enterrando el caso español*
}

\author{
Historical memory, body and performance. Burying the Spanish case
}

Memória histórica, corpo e performance. Enterrando o caso espanhol

\section{Luis Cemillán Casis**}

Universidad Carlos III de Madrid, España

Correo electrónico: luisergo95@hotmail.com

Revista Corpo-grafías: Estudios críticos de y desde los cuerpos / Volumen 5 - Número 5 / Enero - diciembre de 2018 / ISSN impreso 2390-0288, ISSN digital 2590-9398 / Bogotá, D.C., Colombia / pp. 88-101.

Fecha de recepción: 24 de mayo de 2017

Fecha de aceptación: 9 de julio de 2017

Doi: https://doi.org/10.14483/25909398.14208

Cómo citar este artículo: Cemillán, L. (2018, enero-diciembre). Memoria histórica, cuerpo y performance. Enterrando el caso español. Revista Corpo-grafías: Estudios críticos de y desde los cuerpos, 5(5), p-p 88-101/ ISSN 2390-0288.

*Artículo de reflexión investigación: El presente artículo deriva de la investigación realizada por Luis Cemillán Casis, bajo la orientación de Juan Albarrán, durante el curso académico 2017-2018 en el marco del Máster en Historia del Arte Contemporáneo y Cultura Visual (Universidad Autónoma de Madrid, Universidad Complutense de Madrid, Museo Nacional Centro de Arte Reina Sofía).

**Graduado en Comunicación Audiovisual por la Universidad Carlos III de Madrid (2013-2017), con intensificación formativa en el campo del cine y de las industrias culturales. Actualmente, se encuentra finalizando los estudios de Máster en Historia del Arte Contemporáneo y Cultura Visual de la Universidad Complutense de Madrid, Universidad Autónoma de Madrid y el Museo Nacional Centro de Arte Reina Sofía.

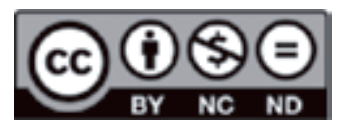




\section{Resumen}

Este pequeño trabajo se propone reflexionar, en un plano de corte ontológico, sobre la relación entre el activismo político en clave de memoria histórica y el arte performativo en el contexto español post-transicional. Veremos, a través de dos casos de estudio recientes (los artistas Luis Melón Arroyo y Abel Azcona) qué mecanismos advienen de la puesta en relación de las disciplinas de la performance y la memoria, y cómo ambas retornan al cuerpo como material significante y como enlace de contacto (terminológico). Trataremos así de reivindicar la idoneidad y, en muchos casos, necesaria recurrencia a las prácticas artístico-performativas para significar un vacío (el de la memoria de los desaparecidos) promovido por un Estado que hace operar su maquinaria simbólica como un anatema.

Palabras clave: memoria histórica; cuerpo disidente; desaparecido; arte de acción.

\section{Abstract}

This work tends to think, on an ontological sense, about the relation between the political activism, in the key of historic memory, and the performative art in the post-transitional Spanish context. We will see, through two recent case studies (Luis Melón Arroyo and Abel Azcona) what mechanisms come from the relationship between the disciplines of performance and memory politics, and how both return to the body as a significant material and as a contact link. We will try to reclaim the suitability and, in other cases, a recurrence to artistic-performative practices to signify a hole (the memory of the disappeared) promoted by a State that makes its symbolic machinery operate as an anathema.

Keywords: historic memory; dissident body; missing person; performance.

\section{Resumo}

Este trabalho tende a pensar, num sentido ontológico, sobre a relação entre o ativismo político, na chave da memória histórica, e a arte performativa no contexto espanhol pós-transicional. Veremos, através de dois estudos de caso recentes (Luis Melón Arroyo e Abel Azcona), quais mecanismos vêm da relação entre as disciplinas de performance e memória política, e como ambos retornam ao corpo como um material significativo e como um elo de contato. Tentaremos recuperar a adequação e, em outros casos, a recorrência às práticas artístico-performáticas para significar um buraco (a memória dos desaparecidos) promovido por um Estado que faz com que seu maquinário simbólico funcione como um anátema.

Palavras-chave: memória; corpo disidente; desapareceu; performance. 
En segundo lugar y de forma paralela, no coincidente, el siglo XX ha supuesto para el arte contemporáneo, entre muchas otras rupturas, la progresiva desobjetualización de la obra de arte y la desterritorialización de la práctica artística respecto del museo. Body art, happening y performance son algunas de las prácticas que comienzan su recorrido en la escena e historiografía artística internacional. Pero también cobran relevancia otras cuestiones como el interés por la deconstrucción de la autoría, la invasión del entorno urbano (entendido desde su dimensión física de espacio público), la fusión utópica entre activismo/política y arte, la puesta en crisis de los roles jerárquicos de productores y receptores de la obra.

O bien nadie, o cualquiera, podría atreverse a establecer una correlación entre ambas disciplinas: la de la memoria histórica y la del arte de acción. Puesto que ambas gozan, a día de hoy, de una trayectoria historiográfica en detalle teorizada y, podría decirse, esencialmente excluyente. Pero, al mismo tiempo, abundantes son las publicaciones que deciden acercarse al fenómeno de la violencia política desde ambas disciplinas. El enunciado que inicia El espectáculo de la memoria (2000), el reconocido artículo de Diana Taylor, demuestra el mutuo deseo de diálogo: La memoria es un fenómeno del presente, una puesta en escena actual de un evento que tiene sus raíces en el pasado (Taylor, 2000, p.34). Los términos presente y puesta en escena no solo son reconocidos por aquellos que se dedican al estudio de la estética performativa, sino por aquellos otros cuya voluntad ansía que se hable de memoria para referirse al presente. $Y$ Taylor continúa: a través de la performance, se transmite la memoria colectiva; puesto que la memoria es capaz de sacar a la escena pública el trauma individual silenciado, o bien enterrado; y de idéntica hacienda puede encargarse una práctica performativa. Como Richard Schechner, defiende en su introducción a los Performance Studies: "performance occur in eight sometimes separate, sometimes overlapping situations: In everyday life (cooking, socializing, "just living"); in the arts; in sports or other popular entertainments; in business, in ritual..." (2013). Cabe preguntarse por qué no podría compartir, también, escena con la memoria.

Este trabajo se propone reflexionar, en un plano ontológico, casi esencialista, sobre la relación entre el activismo político en clave de memoria histórica y el arte performativo. Caeremos, seguramente, en generalidades ya ensayadas. Y parecerá que nos olvidaremos, como empezaba diciendo, de la enorme trayectoria de análisis de las que ambas disciplinas se sirven. Pero nunca debería perjudicar poner a dialogar conceptos de partida en ambos sentidos. Pues, como me referiré también, aún queda mucho trabajo para desvelar, en concreto, el caso español. Algo debe ocurrir si en el segundo país con mayor número de fosas comunes pendientes de exhumar se evita, incluso parece molestar referirse, o tan solo recordar, este tema.

Veremos, a través de dos casos de estudio a modo de ejemplos, qué mecanismos advienen de la puesta en relación de las disciplinas de la performance y la memoria, y cómo ambas retornan al cuerpo como material significante. Empezaremos, a modo de introducción, reseñando un pequeño marco que nos permitirá adentrarnos y ponerle verbos al diálogo que pretendemos establecer. Es entonces cuando el concepto de cuerpo nos permitirá enlazar los puntos de contacto (terminológicos) entre disciplinas.

\section{Ante la falta de imagen...}

La reflexión acerca del trauma tiene que ver, para muchos teóricos y teóricas, con la representación gráfica, simbólica e icónica del dolor, de la barbarie y los archivos que esta genera. El imaginario en torno a Auschwitz, como ya se sabe, supuso un crucial punto de inflexión, pues impregnó al mundo artístico occidental de una crisis simbólica, al tiempo que desde entonces se han estetizado y serializado las fórmulas del altar y puesta en escena del dolor (la fotografía de tipo carnet acompañada de ramajes de flores y velas a la hora de asumir la violencia de cualquier tipo de registro icónico de la barbarie). El estudio de las imágenes de la violencia puede, a parte, de testimoniar y 
de servir como documento histórico del conflicto y las víctimas, hablar de muchas cosas: puede provocar la náusea o el rechazo; incitar al mito que generan; desvelar el juego de posiciones y jerarquías que se establece entre el sujeto distante que mira y el objeto desfigurado observado (que siempre es hecho distante por otro); o también favorecer el uso dialéctico, político, de propaganda incluso en conflictos armados; así como permitir reflexionar sobre si existe una manera justa de contemplar, humanizar, ese horror. Curiosamente, muchos de estos trabajos parecen partir, a sorpresa nuestra, de los grabados de Francisco de Goya:

Uno de los grabados más inquietantes y sobrecogedores de "Los desastres de la guerra" de Goya lleva un título que no deja espacio a la ambigüedad interpretativa: "No se puede mirar". Es como si dijera que quien no puede mirar no puede ver, por lo que el proceso cognitivo quedaría descartado a priori (Stucki y López de Abiada, 2004, p.103).

Nos interesa hacernos la pregunta que sigue a dicha cita, aunque en sentido contrario: al ¿cómo llegar, entonces, a ese proceso cognitivo? le añadimos ¿cómo llegar, entonces, a ese proceso cognitivo si se carece de imagen a la que regresar? Sería muy interesante plantearse todas las cuestiones antes referidas para analizar el caso de la violencia política franquista ejercida desde el Estado español, desde la represión de posguerra hasta las torturas durante la transición. Pero ¿qué cuestiones acerca de la imagen de la barbarie pueden pensarse si dicha imagen, o ha sido borrada, o quizás nunca fue tomada? Evidentemente se conservan y han llegado hasta nuestros ojos algunos archivos de la represión franquista, en especial imágenes sobre los fusilamientos. Pero, por lo general, existe en el imaginario colectivo una fuga que marca la ausencia de la iconografía sobre todas las víctimas desaparecidas, torturadas y asesinadas por la represión franquista. Los análisis se limitan a aproximar la ubicación donde se hallan las fosas, donde se encuentran los que fueron lugares de tortura. Pero, aun consiguiendo practicar las exhumaciones o re-significaciones simbólicas, hay algo de lo que siempre careceremos: la imagen fotográfica originaria, indicia ${ }^{2}$,

del cuerpo torturado, fusilado y enterrado; de la primera apertura del abismo en tierra para taparlo y nunca más sellarlo.

Lo siguiente que cabría preguntarse es: ¿por qué no hay imagen? A lo que, prematuramente, se puede advenir: sí la hay; en las calles y monumentos de las principales capitales de provincia, también en los pueblos, hay una imagen que permite llorar a unos (lo que instauró el régimen dictatorial) y olvidar a otros. Y muchos son los ejemplos que reconocemos: el Valle de los Caídos (como máximo exponente), el callejero de Madrid, Barcelona y muchas otras capitales. Por tanto, pensaríamos que si un Estado que ha proyectado y fijado su identidad en la lógica monumental (y más si se trata de un Estado fascista), ante un inminente cambio de políticas (la transición a la democracia), uno de los motivos de la agenda debiera haber sido la reconfiguración de aquello que explica y legitima, en parte, el espacio público. Es decir, haber intentado recuperar y conmemorar esa imagen borrada y reinterpretar la conmemorada. Rafael Escudero (2013) deja claro que los asuntos de memoria histórica no protagonizaron el cauce de la transición y, sin embargo, años después han terminado por definirla. Aunque sobre la agenda no se tratasen las políticas de memoria, sí lo hicieron las de desmemoria ${ }^{3}$. Por tanto y a pesar de que la versión oficial e incluso internacional presente a la transición como un proceso modélico, podríamos aventurar que si dicha imagen ha sido generada en torno a los protagonistas artífices de la misma es porque se ha buscado construir o direccionar la mirada hacia una memoria oficial: la del "consenso". Por tanto, si el pacto que mira y emana de la dictadura elige formularse sobre el silencio, conviene tener en cuenta, y ya nos aproximamos a los casos de estudio, el concepto de olvido.

\footnotetext{
2 La confianza según la cual aquello que queda representado en la fotografía analógica es índice de que ha estado presente en escena.

3 Tres son las claves que destaca Escudero y que se formalizaron en el plano jurídico/político: el protagonismo de las propias instituciones y mecanismos franquistas a la hora de formalizar una de las leyes más importantes del cambio de régimen (la Ley 1/1977, de 4 de enero para la Reforma Política), y que nos habla de que la propia Transición se concibe como un proceso de reforma y no como una ruptura radical con el franquismo (Escudero, 2013, p.323); la amnesia, por la que se recurre o solicita el silencio sobre la violencia política del régimen; y la amnistía, traducción al derecho de esa amnesia promulgada en 1977, antes de la Constitución del 1978 y posterior a la muerte de Francisco Franco, de tal forma que en democracia se ha imposibilitado la condena a aquellas instancias, organismos o personas jurídicas que emplearon la violencia institucional durante la dictadura.
} 
Heidegger, citado por Huyssen (2004), reconoce que la memoria solo es posible a partir del olvido y no al contrario. Y sigue el segundo: "es necesario localizar el olvido en un campo de términos y de fenómenos tales como el silencio, ausencia de comunicación, desarticulación, evasión, represión..." (Huyssen, 2004, p.3). Esto es, que los silencios denotan la presencia de ausencias estructurales, manifestadas en la incapacidad de narrar. Si tomamos la alegoría de Raunig en Algunos fragmentos sobre las máquinas (2008) acerca del funcionamiento maquínico del modo de operar lingüística y simbólicamente de la sociedad (que él emplea para analizar el EuroMayDay de 2005), nos damos cuenta de que la ausencia de imágenes de la represión franquista, la voluntad de no interferir en su pérdida y el interés porque las que hubiera pasen al olvido; todo ello se mueve acorde a una maquinaria simbólica que opera desde varios ámbitos (la política, medios, opinión pública e historia) como ejercicio de la hegemonía de poder. Si, como puntualiza Ana Lucía Cervio (2010), la facultad de recordar (la memoria) es lo que otorga a los sujetos la entidad de ser social, y si ese ser social es borrado por una maquinaria sistemática de la vida pública ¿qué se puede hacer para recuperar, o problematizar, la memoria?

Como trataré de justificar a continuación, tras un marco de apertura un tanto extenso (pero a cuyos conceptos, memoria-no-imagenolvido, volveremos), los engranajes han de girar de otra manera si se quiere subvertir la máquina. Es en este concepto del movimiento y lo maquínico donde ponemos a dialogar el concepto de memoria histórica con las prácticas performativas del cuerpo; donde trataremos de demostrar cómo no solo permiten el recuerdo sino la problematización de todos los conceptos tratados en este punto y que sitúan, por definición, a un Estado (el español) que opera como anatema. Como dice Nelly Richard: "el arte crítico necesita interrumpir, aunque sea por un momento, la velocidad de este flujo mediático (...) que nace del duelo irresuelto de una memoria faltante todavía en suspenso" (Richard, 2007). Decimos: la memoria interrumpe; la performance, también.

\section{...es preciso moverla, generarla}

\section{Cuerpo}

El tiempo, que siempre es relativo y escurridizo, olvida. O quizás es el olvido el que requiere del tiempo para suceder. Recuperar las cifras, las listas que elabora el propio paso de la historia puede necesitar varias décadas para permanecer en la memoria, y tan sólo 16 horas para volver a ser elaboradas. El 12 de septiembre de 2015, el artista Luis Melón Arroyo, escribió durante horas, con tiza, sobre la piedra de la plaza de San Marcos de la ciudad de León los nombres de los más de 6.000 presos políticos que fueron torturados y asesinados por el Estado franquista en el edificio donde se sitúa ahora el Parador de Turismo de la ciudad. Vecinos, familiares y transeúntes pudieron curiosear y participar de esta práctica que se enmarcaba dentro de las actividades celebradas por el 15 aniversario de la Asociación para la Recuperación de la Memoria Histórica4

4 Visualizar las fotografías en los registros de la prensa. Por ejemplo: Otero, Eloísa (2015). A manguerazos contra la Memoria Histórica. ARMH, 17 de septiembre. En línea http://memoriahistorica.org.es/tag/luis-melon-arroyo/ 
En ese mismo año, pero en Pamplona, Abel Azcona enterró a más de una decena de personas (en su mayoría familiares o descendientes de víctimas del franquismo) bajo la lluvia que caía sobre la explanada del Monumento a los Caídos, donde siguen enterrados y conmemorados los restos de los generales franquistas Emilio Mola y José Sanjurjo 5 . Azcona, colocó uno a uno en el suelo a los participantes (previamente localizados y convocados a través de una búsqueda por las redes e internet), en un gesto valiente y respetuoso, ocupando el centro de una plaza "plagada de símbolos franquistas semiocultos que, según la Ley de Símbolos de Navarra, deberían haber sido retirados" (Azcona, 2015) ${ }^{6}$.

No hace falta añadir ningún prólogo para entender el nexo que imbrica a las dos disciplinas que dialogan en este trabajo: si el cuerpo y la voz son los instrumentos fundamentales de la historia, de la vida incluso, la falta (provocada) de ambos justifica su empleo como herramientas de la memoria, a través de los nombres y los testimonios o el relato oral. Pero el cuerpo es también la herramienta fundamental del arte de acción o performativo, en cuanto materializa el objeto y sujeto de expresión. A la relación con el cuerpo nos referiremos a través de dos aproximaciones: la huella indicial y la metonímica.

Ambos casos de estudio parten de una premisa ya analizada: la falta de huella indicial (imagen fotográfica) alude a unos cuerpos no solo no presentes, sino carentes de imagen a la que regresar; esto es, desaparecidos y no buscados. Escribir sobre el suelo los nombres de un sujeto-cuerpo exiliado, fusilado, deshonrado, mutilado, maltratado, enterrado es el recurso fundamental por el que la identidad, la esencia, la dignidad transmutan en la memoria y evitan caer en ese olvido que, ya hemos visto, es provocado. Escenificar o visibilizar esa otra imagen nunca tomada, ajena por tanto a los circuitos de circulación de la iconosfera o del imaginario colectivo, es otra forma de nombrar o visibilizar la falta. El entierro de los cuerpos que lleva a cabo Azcona (y las fotografías tomadas a su costa) muestran la imagen que no existe, que no puede ser llorada, como aludíamos en el marco teórico, y hacia la que no se puede regresar: se calcula que 114.000 personas están enterradas en tierra de nadie (y por la que todos pisan) y, gracias a las asociaciones de memoria, a costa de la ayuda institucional gubernamental (al menos a escala nacional), parte de esos cuerpos en forma de huesos pueden ser identificados y nombrados, sacados del olvido público. Pero, aunque semejante hazaña (pues es un logro hoy en día) se consiga, la performance de Azcona, impregna en nuestra retina la imagen del primer entierro que nunca llegaremos a ver; la imagen del verdugo condenando a la víctima. La imagen que, por no existir, salva, precisamente, a quien cometió los crímenes, pero no quiso dejar testigos. La imagen que solo nos llega transmutada en forma de lista. Como decía antes: en la representación del dolor se elige llorar a las víctimas en forma de lista; pero en el caso de los desaparecidos, es la única opción.

Por tanto, ambos trabajos, pero sobre todo el de Azcona, nos hacen pensar en un plano de búsqueda indicial (la huella de lo visible), en el deseo de encarnar la memoria; esto es, hacerla cuerpo, concediéndole un registro físico e icónico a la gramática de olvido. En palabras de Agamben: "el cuerpo es el principio de la política, en la medida en que su actuar, su dirigirse a otros, implica de entrada una intensidad que se expresa políticamente" (citado en Martínez Quintero, 2013, p. 46). Intensidad que es exposición, riesgo, exterioridad.

La recuperación o encarnación de la imagen-identidad-nombre-cuerpo como documento nos habla de uno de los propósitos de la memoria: la reparación, que implica nombrar, codificar y consignar la violencia. Incluso la propia arena usada en el enterramiento es atravesada por la personificación del cuerpo, ya que procede de una huerta con nombres y apellidos: la tierra de Arcadio Ibáñez San Juan, cuyo padre y cuatro tíos fueron asesinados por la represión franquista, aun en paradero desconocido.

5 Emilio Mola fue uno de los cabecillas que dirigieron el golpe de Estado de 1936, desencadenante de la Guerra Civil. Sanjurjo también estuvo implicado, pero se le conoce por planear otro intento, fallido, de golpe militar en 1932 durante la Segunda República.

6 Visualizar las fotografías en los registros de la prensa. Por ejemplo: Agencia Efe. (2006). Abel Azcona entierra simbólicamente a familiares de fusilados en una "performance". 1 de mayo. En línea https://www.efe.com/efe/espana/sociedad/abel-azcona-entierra-simbolicamente-a-familiares-de-fusilados-en-una-performance/10004-2601399 


\section{Intervención, en presente}

Sin embargo, la búsqueda que hemos definido como indicial ante la ausencia de dicho índice fotográfico no es la única forma de definir al cuerpo. Trabajar con la performance permite expandir el campo de análisis.

Richard Schechner, sostiene en la introducción a sus Performance Studies, que la esencia de un evento (performativo, se entiende) no depende únicamente de la materialidad, sino también de la interactividad; es decir que el texto esté siempre en circulación y relación. Ante la pregunta, Where do performances take place? (Schechner, 2013, p.30) el autor acude a los conceptos acción, interacción y relación para dar respuesta. Asimismo, Peggy Phelan ya había sentenciado que la única vida del performance transcurre en el presente (2011, p.97), diferenciando así la expectación vivencial de la acción frente a su documentación o registro. Si antes veíamos cómo las acciones analizadas dependían de la relación entre productor/receptor, es la dimensión relacional en la que la performance toma lugar y la que, además, sitúa en crisis el binarismo antes citado. De la misma manera, Harvey (reflexiona sobre lo relacional y temporal de la memoria,

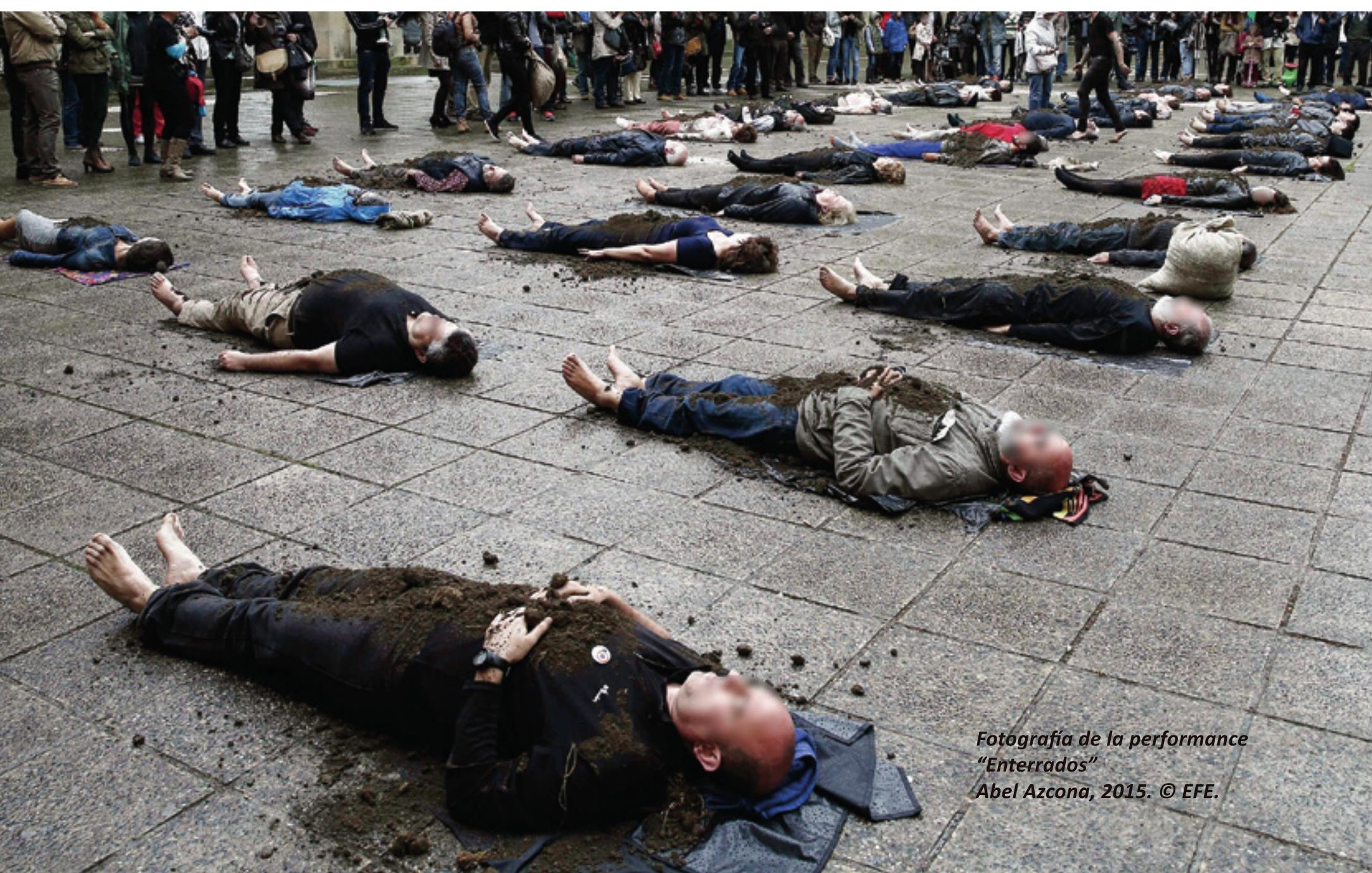


en tanto, se sitúa en ese intersticio entre el espacio y el tiempo: los "lugares llegan a construirse por procesos dinámicos de relativa permanencia y que son inherentes a la influencia del tiempo" (citado en de Paz, 2016, p.23). Es evidente cómo, tanto para la memoria como para la performance, existe un criterio de selección, relectura y construcción de otros estadios (como el pasado) que se configuran en presente a modo de proceso en constante revisión. Como recoge Ana Lucía Cervio (2010), "la experiencia pasada no es una relación exterior objetivada/reificada, sino el producto siempre renovado de prácticas colectivas que la reinterpretan para ser recomenzada y reconstruida en términos de la acción presente" (Cervio, 2010, p.74). Y para más inri, Taylor (2000) establece una estrecha relación entre la noción de performance (que supone un repertorio reiterado de conductas repetidas) y la de trauma, que regresa y se manifiesta corporalmente mucho después de su origen.

Conviene recordar, asimismo, frente al concepto memoria-documento, el término memoria performativa que también Taylor (2000) emplea para referirse a aquellas experiencias de la barbarie que no pueden ser nombradas de forma narrativa o archivística. Representaciones que abogan por una dimensión estética de la documentalización, trascendiendo lo espacial, textual e histórico al ubicarse en espacios de dimensión corporal y emocional, de hábitos y acciones y conexión de lo privado con lo público (de lo individual a lo colectivo) como escenario de identidad y resistencia. Frente a la acción de fijar el recuerdo en los monumentos, que supone concebir la historia como ejercicio sellado, la diferencia entre desaparecido y muerto hace compleja la asunción de procesos que fijen unas memorias definitivas (Ricart, 2017); frente a ello, la intervención en el espacio obliga a repensar y transitar los lugares sobre los que se pretende un ejercicio de memoria, siempre en constante revisión e interferencia y que definen a los cuerpos que los transitan. De esta manera, la idea de que la performance es un proceso que sucede en un presente y que altera o codifica de distinta manera a la temporalidad fijada por la lógica de la historia y la imagen-monumento nos permite, ahora sí, referirnos al otro tipo de relación que utilizaremos para referirnos al estudio del cuerpo: la escenificación metonímica y colectiva.

Por una parte, la imposibilidad de mirar a los ojos (de los nombres en forma de listado o de quienes yacen enterrados) es lo que localiza al cuerpo suspendido: la incapacidad del espectador para encontrarse con su mirada "define" al cuerpo del otro como perdido (Phelan, 2011). Esto es, la escenificación tiene lugar en esa raya entre lo presente/ausente. Es evidente que la imagen indicial a la que aludíamos antes no es más que una búsqueda o aproximación ideal, pues en efecto el mecanismo que realmente opera sobre los cuerpos es el de la metonimia, en el sentido de que "el yo actúa como otro: quien recuerda se convierte en otro porque asume simultáneamente el papel de personaje de la trama y coautor de sentido" (Cervio, 2010, p.73). Decíamos que estos casos vertebran entre lo dicho y lo no dicho, pues la propia posibilidad de que los familiares sean los que en 2015 se entierren (ficticiamente, escénicamente) para volver a ser desenterrados en condiciones de normalidad evidencia que son cuerpos que sobreviven, que perduran y re-encarnan a los que se les negó tal destino. Si hay un cuerpo allí representando es porque falta el representado. En ideas de Agamben: "el testimonio lleva en sí mismo los signos de su propia limitación, su propia laguna, pues, quienes podrían ofrecer el relato más ajustado a la forma como se dieron los hechos de violencia son precisamente los que no pueden testimoniar" (citado en Martínez Quintero, 2013, p.49). El testimonio está constituido por lo indecible: en él hay algo como una imposibilidad de testimoniar, que sólo se transmite en cuerpo (del performer) tan incorpóreo como la propia voz: soporte, medio e inscripción.

Por otra parte, la relación colectiva que define el plano de la producción o configuración de la obra/escena/relato pone en cuestión otra problemática que afecta a los casos de estudio: el límite entre la relación y jerarquización de la producción/recepción objeto-cuerposujeto, cuerpo-sujeto-objeto. Es decir, la alteración de la condición enunciador/enunciatario que la historia y el monumento fijan, pero la performance y memoria problematizan. En este sentido, el carácter colectivo de la escena es ejemplificado a través de la propia 
dinámica performativa mediante la desviación o puesta en cuestionamiento del papel del productor y espectador. En términos de Phelan (2011), el arte distingue en esencia entre el artista-sujeto (que crea la obra) y el objeto (como artefacto separable, fijable, transmisible). Tradicionalmente, esta relación de tintes jerárquicos ha establecido, por una parte, una distancia y, por otra, la posibilidad de posicionarse reiteradamente frente al objeto, proyectando significados que continuamente se van renovando. Cuando Fischer analiza el trabajo de Marina Abramović en su Fundamentos para una estética de lo performativo, extrae la idea de que los espectadores, al compartir espacio, tiempo y efimericidad se convierten en co-sujetos. De esta manera, la performance, al igual que sella el espacio, marca, limita, define a quien lo transita mientras toma lugar. El viandante o turista que normalmente camina sin interferir en el mobiliario público, como quien evita el prohibido contacto con las obras de un museo, o sin cuestionarse el ritmo del transitar, se transforma, en la performance, en espectador de su propia vía. El espacio público queda marcado. El andar desenfrenado se hace imposible si supone pasar sobre unos cuerpos que descansan en el camino (los colocados por Azcona), así como el viandante que decidiera atravesar la plaza del Parador lo hiciera a costa pisotear y borrar con cómplice descuido los nombres grabados con tiza. De alguna manera, se busca generar una especie de "responsabilidad compartida con respecto a la violencia política" (Albarrán, 2013, p.312). Luego veremos qué ocurrió con las performances de las que hablamos.

En definitiva, frente a la mirada contemplativa, distanciada, productiva que se suele tomar en el contexto de la violencia política silenciada (la versión oficial del Estado a la que aludíamos en la introducción), los procesos de memorialización, en tanto performativos, permiten una ubicación (mirada) activa, que siempre que interviene reactiva una presencia (en presente), una escritura (en proceso) potencialmente abierta al cambio, a la que concluir significaría silenciar. Pues dichos cuerpos y recuerdos existen en tanto se pronuncian los individuos que los portan (Ricart, 2017).

\section{A modo de punto y seguido}

Remitirnos a un último concepto puede ayudarnos a concluir este diálogo entre las disciplinas de la memoria y la performance: lo "efímero" nos retrotrae, a modo de conclusión, a la idea del silencio institucional como máquina.

Desde la primera exhumación con criterios científicos con la que se dio paso al cambio de siglo y con la que abríamos estas líneas, algunos han sido los avances en materia y políticas de Memoria Histórica, a partir también de las presiones de la ONU por priorizar la búsqueda de los desaparecidos y hacer justicia así a los conceptos del Derecho Internacional: Verdad, Justicia y Reparación. La Ley de la Memoria Histórica (Ley 52/2007 de 26 de diciembre), propuesta por el Partido Socialista Obrero Español (PSOE) evidencia la iniciativa gubernamental por intervenir y conceder prioridad, pública y nacional, a la recuperación y peticiones de las asociaciones. No obstante, Rafael Escudero (2013) analiza no solo las dificultades que supuso para el propio PSOE una discusión a nivel interno en materia de la ley, sino que esboza varios planteamientos que intentan explicar la inoperancia de la misma7. Que la propia iniciativa del grupo parlamentario

7 En su título oficial, la principal ausencia que destaca es la del propio concepto de memoria histórica, ya que no se acoge esta expresión en su título. Además de la escasa extensión del texto, el segundo problema que plantea es que no cuestiona el pacto de la transición (ni, por tanto, la ley de Amnistía). Por otra parte, además del texto de Escudero destacamos otras críticas a la misma. La declaración de reparación y reconocimiento personal que propone la ley no tiene efecto jurídico alguno, y el proceso para realizar las exhumaciones resulta complejo y burocrático. En vez de partir de la iniciativa estatal, son las asociaciones las que deben primero elaborar un presupuesto, a posterior valoración y aprobación (o no) por parte del Gobierno. Un procedimiento similar al de las excavaciones arqueológicas, y que parece no atender al factor personal, que puede resultar inoperante y conflictivo (puesto que, en función de la Ley General de Presupuestos del Estado, el Gobierno decidirá qué iniciativas subvencionar y cuáles no, por lo que subyace la idea de que unas víctimas son más importantes que otras). Entre otros conflictos, este último es el que permitió que la firmeza con la que Mariano Rajoy, líder de la oposición, enunciara en la Campaña Electoral de 2011 su interés por derogar la ley, terminase en un grito sin consecución; pues no era necesario. Tan solo con suprimir la partida de presupuestos dedicada a las subvenciones consiguió desligar, de nuevo, interés gubernamental y exhumación. El Diario.es (diciembre 2017) Fosas sin excavar, símbolos fascistas y nula financiación: diez años de fracaso de la ley de Memoria Histórica. http://www.eldiario.es/sociedad/simbolos-financiacion-acabado-desmemoria-historica_0_723028328.html 
afín ideológicamente, en principio, a la causa memorialística sea insuficiente e incluso inoperante, nos habla de un continuum de prácticas que mueven o arrastran la maquinaria del silencio o amnesia de la Transición. Una rápida y fortuita búsqueda en las páginas de las asociaciones y de algunos diarios visibiliza un discurso de la memoria que, como critican los grupos conservadores, nada tiene que ver con el pasado. Mientras los cuerpos permanecen en el olvido, desternillantes, preocupantes e incluso condenables actitudes por parte del Partido Popular (PP), en su mayoría, demuestran una enorme preocupación por relegar (desde el presente) al olvido aquello que va contra sus políticas (del presente), confinando el ejercicio de la memoria al ámbito residual, local, individual'; dejando inhabilitada la iniciativa de ciudadanos, víctimas y asociaciones, al no disponer, evidentemente, de recursos si quiera para colocar o cambiar los memoriales.

Es decir, la iniciativa institucional de desmemoria perdura mientras las prácticas relacionadas con la memoria continúan siendo, como ella misma se define, efímeras (en el sentido de que deben estar continuamente fijándose y revisitándose, transmitiéndose para no desaparecer)9. De nuevo, resulta evidente la similitud con la que se pretende cerrar el texto. La preocupación de las teorías que se aproximan al estudio (ontológico) de la performance señalan su intrínseco y casi obligado carácter efímero, pues la obra (definida anteriormente como cuerpo-relación-espacio/tiempo) tiene lugar únicamente mientras se está realizando:

\section{El performance rechaza este sistema de intercambio y se resiste a la economía circulatoria fundamental en la escritura}

y el discurso. El performance honra la idea de que una cantidad limitada de personas en un marco específico de

tiempo/espacio participe de una experiencia valiosa que no deja huella visible tras de sí (Phelan, 2011).

Lo interesante así, es cómo la marca que la performance señala en los cuerpos los conecta, genéticamente, filialmente y políticamente; pero, ante todo, lo hace de manera efímera. La propuesta de Abel Azcona retornó al orden como la lluvia se marcha: sin avisar. Los cuerpos, terminada la función, recogieron, limpiaron, se levantaron y continuaron con sus quehaceres. Al fin y al cabo, solo el símbolo podía quedarse allí. Pero para tristeza e indignación de muchos, los 6.000 nombres de Arroyo no fueron borrados con la tímida mirada cómplice de quien calla, sino con la intencionalidad del grito. A las doce de la noche del mismo día, varios camiones del Ayuntamiento se encargaron de borrar los nombres a manguerazos. Puede que no lo supieran, pero estaban formando parte, como cuerpos marcados, de la performance. Solo que encarnaron, no a aquellos cuerpos que siguen suspendidos, sino los que visten esa presencia que persigue la ausencia. Los cuerpos que continúan enterrando el pasado.

¿Qué queda, entonces, de todos ellos? Al igual que escribir sobre performance enuncia esa imposibilidad de fijar lo irrepetible del acto, de las prácticas analizadas solo queda el registro documental a partir de las fotografías tomadas o incluso de los vídeos elaborados, así como el comisariado de alguna exposición que ha recogido los procesos ${ }^{10}$. Pero en cualquier caso las prácticas en torno a la memoria histórica y la performance nos hablan de esa necesaria transmisión de unos procesos cuya permanencia requieren de un continuo esfuerzo por comunicarse; por causa de un Estado que así lo quiere.

8 Consultar los artículos de prensa en las referencias bibliográficas.

9 Urgente pues, que desde el ámbito de la Academia sea donde se discutan y problematicen estos conceptos, pero también contemplar la práctica artística (y debiera ser su necesaria crítica) como puente de unión entre institución-pensamiento y acción-vida. Así, Joan Gibbons parte de la premisa de que, en la actualidad, (...) el arte se ha convertido en uno de los medios más importantes para llevar a cabo aquel "trabajo de memoria" (memory work) que la cultura contemporánea requiere. (Hermosilla, 2012).

10 El diario norte (enero 2016) La exposición de Abel Azcona, la más vista en el antiguo Monumento de los Caídos. http://www.eldiario.es/norte/navarra/ultima_hora/ exposicion-Abel-Azcona-Monumento-Caidos_0_474902944.html 
En definitiva, la performance se configura como un tipo de práctica artística cuyas condiciones pueden emular el propio discurso de la memoria histórica: la recuperación del cuerpo, que se hace individual en lo colectivo, público en lo privado, a través de una doble relación (indicial y metonímica) que dialoga con la relación entre el yo/otro; que politiza el escenario donde tiene lugar y lo re-configura o resignifica, ya no solo como escenario performativo (propenso a estar en constante proceso de relectura) sino como esfera pública; cuya lógica de escritura en y desde el constante presente problematiza la lógica del monumento asociada al olvido, al discurso sellado, fijado; y que, por las condiciones institucionales en las que tiene lugar, está condenada a operar en lo efímero y quedar relegado únicamente, y de nuevo, a las herramientas de la memoria: voz y cuerpo, testimonio ausente y presente. Pero lo más interesante de todo, es que este re-direccionar la máquina (que tiene claramente una contestación institucional en su contra), esta revisión constante, ya no únicamente, evidencia las fallas de la violencia política practicada por el franquismo. Si la desmemoria e inoperancia de las políticas oficiales permiten que sea el ámbito artístico, y no otros, el lugar privilegiado para la denuncia simbólica, evidencian que el cuestionamiento de la memoria histórica y represión franquista tambalea el propio relato de la transición. La forma en la que las instituciones actuales alejan del debate público al contra-relato simbólico, permitido a través de la performance (como estado de excepción), evidencia la preocupación por evitar desestabilizar una versión histórica nacida en la transición y que, por tanto, y en último lugar, estaría hablando de una debilidad de las propias bases sobre las que se asienta el sistema democrático. En definitiva, cuestionar, hoy día, el relato del olvido significa cuestionar, en sí, el valor de la Transición. Y con ella, el sustento de la actual democracia. 


\section{Referencias}

Albarrán, D. J. (2013). "Sentir el cuerpo: performance, tortura y masoquismo en el entorno de los nuevos comportamientos", Arte, individuo y sociedad, 25(2), pp. 303-317. Recuperado de http://www.redalyc.org/articulo.oa?id=513551288010.

Albarrán, J. y Estella, I. (2015). “Objetualizar la experiencia, historiar la ausencia. Notas sobre performance y museos”, en Albarrán, J. y Estella, I. (Comp.) Llámalo performance: historia, disciplina y recepción. Madrid: Brumaria.

Arroyo, L.M. (2015). Los nombres [performance]. León.

Azcona, A. (2015). Enterrados [performance]. Pamplona.

Buffery, H. (2017). 2Bodies of Evidence, Resistance and Protest: Embodying the Spanish Civil War on the Contemporary Spanish Stage". BHS. 94(8), pp. 863-882.

Cervio, A. L. (2010). "Recuerdos, silencios y olvidos sobre "lo colectivo que supimos conseguir". Memoria(s) y olvido(s) como mecanismo de soportabilidad social", Cuerpos, emociones y sociedad, 2(2), pp. 71-83.

Díez, E.J. (2013). “La memoria histórica en los libros de texto escolares”, Revista Complutense de Educación, 25(2), pp. 393-409. Escudero, A. R. (2013). Jaque a la Transición: análisis del proceso de recuperación de la memoria histórica, AFD, XXIX, pp. 319-340 Fischer, L. E. (2011). “Fundamentos para una estética de lo performativo”, en Fischer Lichte, E. Estética de lo performativo. Madrid: Abada.

Gerald, R. (2006). Algunos fragmentos sobre las máquinas. Transversal EIPCP. En línea HTTP://eipcp.net/transversal/1106/raunig/es Hermosilla, D. (2012). La memoria y la práctica artística: hacia un estado de la cuestión, en línea https://www.danielahermosilla. com/texts/la-memoria-y-la-pr\%C3\%A1ctica-art\%C3\%ADstica-contempor\%C3\%A1nea-hacia-un-estado-de-la-cuesti\%C3\%B3n-2012spanish-text/

Huyssen, A. (agosto, 2004). Resistencia a la Memoria: los usos y abusos del olvido público, Comunicación presentada en el XXVII Congresso Brasileiro de Ciencias da Comunicaçao, Porto Alegre.

Mandel, C. (mayo, 2008). El arte performativo en las artes visuales contemporáneas: cuerpo y memoria, Comunicación presentada en Jornadas de Cuerpo y Cultura de la UNLP, La Plata

Martínez, F. (2013). “Las prácticas artísticas en la construcción de memoria sobre la violencia y el conflicto”, Eleuthera, 9(2), pp. 39-58.

De Paz, N. (2016). Memoria histórica y arte público. Una aproximación a las prácticas del siglo XXI. Trabajo de maestría, Universitat de Barcelona.

Phelan, P. (2011). “Ontología de la performance: representación sin reproducción”, en Diana Taylor y Marcela Fuentes (Comp.). Estudios avanzados de performance. México: FCE.

Richard, N. (2007). Fracturas de la memoria. Arte y pensamiento crítico, Argentina: Siglo XXI Editores.

Ricart, N. y Paz, N. (2017). “Artistic practices and Memory places. Transmission processes", Ágora, 4(7), pp. 99-130.

Schechner, R. (2013). “What is performance?” En Performance Studies: an introduction (third ed.). London and NY: Routledge.

Schindel, E. (2009). “Inscribir el pasado en el presente: memoria y espacio urbano”, Política y Cultura, 31, pp. 65-87.

Stucki, A. y López, J.M. (2004). “Culturas de la memoria: transición democrática en España y memoria histórica. Una reflexión historiográfica y político-cultural”, Iberoamericana, IV (15), pp. 103-122.

Taylor, D. (2000). “El espectáculo de la memoria: trauma, performance y política”, Teatro del sur, 15, pp. 33-40. 


\section{Artículos en prensa}

Conferencias Reina Sofía. "El instante de la memoria. Narrar la historia", en http://www.museoreinasofia.es/actividades/instantememoria-narrar-historia

El Diario.es. (Enero, 2018). "Defensa se desentiende de la fosa con cien militares fusilados por Franco al mantenerse leales a la República”, (http://www.eldiario.es/sociedad/Defensa-competencia-responsabilidad-asesinados-Franco_0_728277900.html)

El Español. (Abril, 2016). "El Museo del Prado recupera la memoria histórica”, (https://www.elespanol.com/cultura/ arte/20160425/119988164_0.html)

El País. (Octubre, 2013) “El problema de la memoria histórica fue la transición”, (https://elpais.com/sociedad/2013/10/29/ actualidad/1383072050_609425.html)

El País. (Noviembre, 2017). “Melilla defiende por vía judicial la última estatua de Franco", (https://elpais.com/elpais/2017/08/23/ videos/1503498176_527481.html)

El País. (Noviembre, 2017). “Más de 600 vestigios franquistas deberán ser retirados en un año”, (https://elpais.com/ ccaa/2017/11/07/valencia/1510059682_153761.html)

El Plural. (Septiembre, 2015). "El PP borra a manguerazos los nombres de 6.000 presos franquistas". (https://www.elplural. com/2015/09/13/el-pp-borra-a-manguerazos-los-nombres-de-6-000-presos-fraquistas)

Público. (Junio, 2009). “Badajoz levanta un muro contra la memoria” (http://www.publico.es/actualidad/badajoz-levanta-muromemoria.html)

Público. (Marzo, 2016). "Justicia ignora la petición de Argentina de interrogar a Martín Villa y Billy el Niño, entre otros franquistas", (http://www.publico.es/politica/justicia-ignora-peticion-argentina-interrogar.html)

Público. (Abril, 2017). "El 1 de abril y la herida abierta del valle de los caídos", (http://www.publico.es/sociedad/abril-herida-abiertavalle-caidos.html) 